\title{
REPRESENTAÇÃO E IMPERIALISMO EM EDWARD SAID
}

\section{Bruno Sciberras de Carvalho ${ }^{1}$}

\begin{abstract}
Resumo
Com base na suposição de que a cultura e as identidades envolvem um processo construído politicamente, discute-se a importância das concepções de representação e imperialismo na obra de Edward Said. 0 artigo analisa duas propostas gerais do autor. Primeiramente, a tese da centralidade da dimensão cultural nas relações políticas, o que acarreta a revisão de postulados que tomam a cultura ou como mero reflexo de um fenômeno tido por essencial ou como esfera isolada das práticas de poder. Em segundo lugar, examina-se como a concepção de imperialismo do autor serve para se notar formas de identificação que mantêm estruturas de autoridade e hegemonia que, não obstante, podem ser desafiadas por processos de resistência. Por fim, debate-se a validez do caráter aberto da teoria política de Said, que supõe tanto o poder das representações quanto uma ação de contestação política.
\end{abstract}

Palavras-chave: Representação. Imperialismo. Pós-colonialismo. Cultura e Política.

\footnotetext{
${ }^{1}$ Professor Adjunto do Departamento de Ciência Política da UFRJ e do Programa de Pós-Graduação em História Comparada (PPGHC) da UFRJ. Este trabalho está vinculado ao projeto de pesquisa "Pós-colonialismo e Identidade Política: novos argumentos sobre a nação", financiado pela FAPERJ. End. eletrônico: brunosci@msn.com
} 


\title{
REPRESENTATION AND IMPERIALISM IN EDWARD SAID
}

\begin{abstract}
Based on the idea that culture and identities involve a politically built process, the importance of the concepts of representation and imperialism in the work of Edward Said is discussed. The article analyses two of the author's general proposals. Firstly, the thesis of the centrality of cultural dimension in political relations, which leads to the review of postulates that consider culture as a mere reflection of a phenomena seen as essential or as a sphere isolated from the power practices. Secondly, the study examines how the author's conception of imperialism is used as a means of identification that keep structures of authority and hegemony, which, in turn, may be defied by processes of resistance. Finally, the validity of the open character of Said's political theory is debated, which encompasses both the power of representations and an action of political questioning.
\end{abstract}

Keywords: Representation. Imperialism. Post-colonialism. Culture and Politics.

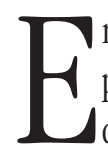

m termos gerais, a teoria de Edward Said, refletindo argumentos do pensamento pós-colonialista, busca desconstruir as definições de verdade do conhecimento ocidental sobre a modernidade, sobretudo pretensões universalistas de uma ciência genérica. Para o campo das ciências sociais, a relevância de sua obra parece estar situada, sobretudo, no exame dos modos pelos quais as formas de identificação social e política se manifestam e se impõem, de um lado, e podem ser contestadas, de outro lado. Nesse sentido, exprime-se um entendimento fecundo da relação entre as dimensões da política e da cultura. Ainda que a cultura reflita um poder estruturado e, em grade parte, uma ordem consensual, é também um campo dinâmico que incorpora conflitos de significação através dos quais a ordem social se reproduz e é experimentada. Ressaltam-se processos complexos de construção de subjetividades abrangentes e os modos como as representações sociais são recebidas e negociadas. 0 âmbito cultural não aparece como um sistema fechado de significados, mas imerso em práticas de conflito que acabam por configurar a possibilidade de uma pluralidade de significações, submetendo-se também a dinâmicas de poder que se constituem continuamente. Na medida em que as relações entre política e cultura são tomadas como instâncias possivelmente instáveis, fundamentalmente, os significados 
sociais se submetem a variados tipos de interpretação, o que pode acarretar tanto uma estrutura consistente quanto a instabilidade política de um sistema.

0 vínculo da cultura com a política pode ser melhor entendido a partir dos mecanismos de representação que refletem poder e pressupostos imperialistas. A concepção de representação na obra de Said, em parte baseada em proposições de Foucault, mostra como o poder condiz com uma dimensão discursiva de produção e elaboração de condutas e pensamento, em vez de ser configurada apenas como algum tipo de restrição ou impedimento às ações. Não sendo exclusivamente determinadas por condições socioeconômicas, as representações são constituídas por dispositivos de conhecimento que têm pretensões de autonomia e verdade, sistematizando um imaginário hegemônico que alcança em determinadas situações uma ordem consensual. Contudo, dado o caráter complexo da cultura, é essa mesma relação com o campo político que, de forma ambivalente, permite resistências e questionamentos dos discursos. Já que a cultura não se apresenta como algo dado ou reflexo de uma essência estruturada, ela pode ser também desafiada, sinalizando, dependendo de certas condições, abertura política pronta para ser mobilizada pelos agentes. Daí a importância dada por Said a perspectivas originais de saber e a outro modelo reflexivo pautado por uma nova crítica secular humanista.

A fim de refletir sobre essas questões, apresento, primeiramente, uma discussão mais detida da articulação entre os âmbitos da cultura e da política em Said, relacionando-a a uma apropriação de outros autores que também enfocaram a centralidade da cultura nas relações de poder, como Raymond Williams, Gramsci e Foucault. Em seguida, mostro a importância do conceito de imperialismo na reflexão de Said, principalmente a sua originalidade em retomar a concepção para 0 entendimento das condições sociopolíticas contemporâneas. Na mesma seção, analiso de que modo o autor pensa as possibilidades de resistência e emancipação em relação a arranjos imperialistas, assim como os problemas de novas práticas nativistas de um nacionalismo fechado. Por fim, busco assinalar virtudes e possíveis problemas expostos nas concepções de representação e imperialismo de Said.

\section{Cultura e Política: RePresentaÇÃo E DISCURSO COMO PODER}

Quando Said articula as dimensões da cultura e da política, sua teoria reflete uma interpretação de certa linhagem teórica que enfatiza o caráter 
fundamental do campo cultural nas relações de poder. Uma das proposições básicas de tal orientação, manifesta na new left inglesa, por exemplo, é criticar as suposições de que a cultura seria um campo neutro e isento de conflitos. Destaca-se a necessidade de reavaliação das superestruturas, que não devem mais ser tidas por reflexos de uma instância verdadeiramente essencial. A cultura, então, participa das contradições dos arranjos sociais e políticos, o que se manifesta nas margens, nos movimentos excluídos e na pluralidade de identidades que não podem ser resumidas ao tipo de conduta da racionalidade instrumental. A diferença torna-se fundamental nessa perspectiva, revelando a possibilidade de agências criativas. Por outro lado, deve-se notar a influência sobre a teoria de Said da relação foucaultiana entre saber e poder, sobretudo o papel que a ciência e intelectuais têm na manutenção de certo sistema de representação. 0 papel da crítica, por conseguinte, é questionar verdades científicas e filosóficas, mostrando as regras que governam sua construção e operam inconscientemente.

Said (1995, p. 76; 2007b, p. 43) destaca a relação de seu pensamento com as teorias de Raymond Williams e Foucault. No caso de Williams, recepciona-se a crítica à visão tradicional do humanismo circunstanciado na ideia de alta cultura que deveria servir como educação moral e retiro espiritual (WILLIAMS, 1979, p. 17-26). Ao contrário dessa visão, a cultura deve ser vista como constitutiva do processo social em geral e da própria atividade material dos agentes. A linguagem e a cultura são vistas como dimensões dinâmicas que não podem ser cristalizadas em uma concepção fechada de superestrutura, indicando questionamento das "teorias do reflexo" em que a cultura espelharia, por exemplo, uma natureza interior ou uma representação falsa da realidade ${ }^{2}$. A dimensão cultural, vinculada a questões de poder, não condiz com discussões estáticas de aproximação da falsidade ou da verdade objetiva, mas sim com processos de hegemonia e, por vezes, com formas criativas de ação (WILLIAMS, 1979, p. 98-100). Uma das formas de reprodução da hegemonia, algo caro à concepção de representação de Said e suas conseqüientes classificações, é a organização da tradição, que se torna uma força ativa e modeladora quando seleciona características do passado e da história, ao mesmo tempo em que se oculta tal seleção (WILLIAMS, 1979, p. 120). Percebe-se como Said, sobretudo a partir da percepção das resistências em

\footnotetext{
${ }^{2}$ Williams (1979, p. 79-92) defende, sobretudo, a necessidade de se voltar a Marx e perceber adequadamente a relação entre pensamento, cultura e atividade material. A intenção é romper com certos idealismos em que as categorias analíticas tomam vida e se tornam concretas, o que exige destacar novamente as contradições entre as relações de produção e as relações sociais.
} 
Cultura e Imperialismo, incorpora a visão da cultura como processo, e não como instância fixa definida por instituições ou formações sem movimento, de modo que a mesma pode se reproduzir ou ser questionada por ações nas margens e por elementos emergentes. Sobressai, então, uma concepção próxima da discussão de Williams (WILLIAMS, 1979, p. 87-92, 125) sobre o determinismo nas relações entre as esferas econômicas, políticas e culturais. Se há condicionamento efetivo entre essas dimensões, essa se situa entre a determinação total e a falta de determinação, algo como uma "fixação de limites" que revela certa objetividade histórica (não abstrata ou idealista), mas também "pressões" que manifestam capacidades de agência e elementos "residuais" ou "emergentes" da cultura.

Já as referências de Said a Foucault são explícitas, por exemplo, na definição singular dos interesses ocidentais em relação ao Oriente (SAID, 2007b, p. 41). Tais interesses não refletiriam apenas intenção político-militar - muito menos estariam vinculados de forma determinista a ela -, mas também uma vontade de compreender, de controlar ou incorporar o tido por diferente, o que caracteriza a conexão do saber com o poder. Há aqui relação com a tese crucial de Foucault (2005, p. 27-48) de não centralizar o exame da política nas dimensões formais do Estado ou das leis, buscando enfatizar, diferentemente, como a produção de verdades condiz com um quadro mais básico de um poder sem centro e não homogêneo, mas que, por isso mesmo, alcança força sem precedentes na modernidade. A fim de compreender tal característica, torna-se necessária uma "análise ascendente" (FOUCAULT, 2005, p. 36) que observe os mecanismos locais ou regionais do poder, demonstrando precisamente a sua circulação, que não se vincula a uma instituição central como 0 aparelho estatal. Nota-se, seguindo esse sentido analítico, que o orientalismo para Said é um discurso que se manifesta em um intercâmbio multifacetado com o poder político, o intelectual, o cultural e 0 moral. Na medida em que os discursos tornam-se preponderantes, revelam que a cultura forma um sistema efetivamente produtivo, definindo um tipo de poder que não é exclusivamente inibidor.

Portanto, uma das grandes contribuições dessas perspectivas é a reelaboração de certa vertente da reflexão política que prefere destacar as relações formais entre sociedade e Estado, como se essas instâncias constituíssem duas esferas apartadas. A obra de Said integra o esforço de teorias que buscam entender as maneiras pelas quais certos arranjos formais reproduzem um tipo normalizado de conduta ou são desafiados pela construção de identidades sociais de resistência. Neste último sentido, procura-se ressaltar a dissociação entre a estrutura dos 
Estados e as estruturas que geram identidades culturais e políticas (EDER, 2003, p. 6). Observar condições culturais hegemônicas requer entender os fundamentos de sua criação, seus agentes e sua história. Já que o poder relaciona-se com a cultura, cabe entender o papel dinâmico e construído da mesma, de modo a definir a genealogia de dado processo político e hegemônico. 0 Estado, por exemplo, não pode ser tido como objeto predeterminado, mas sim como instância inscrita em relações de poder que são anteriores à sua própria existência. Os processos de transformação social e reivindicação política articulam relações de poder e valores disseminados em vários pontos das sociedades.

Nesse sentido, não cabe pensar os processos culturais a partir de um ponto de vista primordial, em que há o compartilhamento de formas específicas de comportamento e comunicação que satisfazem um reconhecimento mútuo sem atritos. A cultura reflete, ao mesmo tempo, o poder das representações e capacidades de agência, o que confere complexidade a cada sistema simbólico. É conveniente, então, negar as afirmações parciais e estáticas de certas teorias da identidade, ressaltando a hibridação e heterogeneidade das interseções socioculturais. 0 ponto fundamental é que as análises devem incorporar também as minorias e movimentos que se opõem aos discursos hegemônicos. Esse é um dos motivos pelos quais a identificação e as representações são vistas como processos politizados, inscritos historicamente no intercâmbio de diversas direções sociais.

Deve-se notar que o tipo de abordagem de Said, quando relaciona cultura e política, difere de grande parte das literaturas da Ciência Política e da Sociologia Política do pós-guerra preocupada com a inscrição do modelo de democracia liberal no mundo e com peculiares formas de "cultura política". A partir de uma perspectiva funcionalista, essas análises procuravam demonstrar como certos valores e atitudes impediam ou beneficiavam o que se concebia como "progresso", de modo que a teoria deveria examinar como o conjunto da população tinha orientações cívicas distantes ou próximas do modelo postulado normativamente (WEDEEN, 2002, p. 713). De forma mais geral, a proposta de Said define certa precedência do âmbito cultural na constituição das relações de poder, ainda que isto não indique, em nenhum momento, um pressuposto de independência da cultura em relação a condições políticas, materiais e econômicas. 0 fato é que a cultura, com base nas representações, define e elabora os próprios interesses pessoais ou imaginações coletivas, que não são dados e não são os mesmos em todas as sociedades (SAID, 2007b, p. 40-41). 
Questões centrais das representações são seus silêncios e exclusões, mais particularmente as tensões entre o que é e o que não é imaginado. Said (2000, p. 424) atenta para mecanismos articulados de interdição, rejeição e vontade de verdade, algo similar à tese dos "procedimentos de exclusão" como forma crucial de ação dos discursos (FOUCAULT, 2001). As representações, sobretudo as nacionalistas, excluem sistematicamente as minorias, que desaparecem do discurso totalizante. Além disso, éfundamental o papel das instituições autorizadas a lidar com uma temática social específica, em sua descrição, reprodução e ensino. Por conseguinte, há relação direta entre um significado definido academicamente e o sentido imaginativo do senso comum, já que o poder se realiza justamente na moldagem e produção discursiva que influi em todo pensamento e ação (SAID, 2007b, p. 29). Não fariam sentido, portanto, as análises que dicotomizam as dimensões da cultura e da política, de modo que haja, de um lado, a esfera cultural isolada, tida como livre e perene, e, de outro lado, uma esfera política que, de fato, seria o verdadeiro lócus da luta de interesses. Chegando a argumentar que cultura e política são, em última análise, a mesma questão, Said expressa que problemas teóricos cruciais aparecem quando "a cultura é exonerada de qualquer envolvimento com o poder, as representações são consideradas apenas como imagens apolíticas a ser analisadas e interpretadas como outras tantas gramáticas intercambiáveis, e julga-se que há um divórcio absoluto entre passado e presente" (SAID, 1995, p. 93). Não à toa, essa direção seria uma das bases mais consistentes do poder dos discursos, que tenta geralmente, em um sentido propriamente foucaultiano (SAID, 1995, p. 153), produzir imagens estéticas e intelectuais com pretensões de autonomia, isenção e verdade.

Said (1995) chama atenção para duas concepções particulares de cultura, de modo a diferenciá-las e defender o argumento da centralidade das representações nas relações de poder. Em um primeiro sentido, a cultura designaria práticas de representação e comunicação que possuem relativa autonomia perante os campos econômico, social e político, e que se manifestam em geral sob formas estéticas. 0 autor inclui aqui tanto o saber popular quanto o conhecimento especializado das disciplinas acadêmicas. 0 ponto fundamental, e o que caracteriza a relação necessária entre política e cultura, seria o poder de construção de narrativas, ou, por outro lado, o poder de impedir que surjam outras narrativas (SAID, 1995, p. 12-13).

0 outro sentido, difundido principalmente pelo humanismo tradicional, define a cultura como conceito que expressa elementos de elevação e refinamento, 
ou uma espécie de reservatório do melhor de cada sociedade nas dimensões do pensamento. Neste último sentido, a cultura poderia neutralizar os problemas da vida moderna e mercantil. Nota-se, entretanto, que esta noção distancia a cultura da política, pois a primeira, caracterizada sobretudo por textos e autores exemplares, é vinculada a uma estética apolítica, depurada de condições históricas e relações sociais ordinárias. Os problemas de tal entendimento, segundo Said, revelam-se no momento em que difundem ou um nacionalismo redutor, baseado na valorização acrítica da alta cultura e tradição nacionais, ou uma filosofia universalista que tende para o transcendentalismo que reivindica, como campo normalizador, grandes realizações culturais, filosóficas e literárias da humanidade.

Said assinala o primeiro sentido de cultura como o mais consistente, pois explicaria efetivamente as formas pelas quais se desenvolvem processos de hegemonia e as tensões políticas que os envolvem. Além disso, tal concepção estaria desvinculada de abordagens que tomam os grupos e sociedades como instâncias fechadas e homogêneas, o que frequentemente tende para suposições nacionalistas que não observam as mediações que perpassam as relações sociais. 0 que caracteriza mais propriamente o sentido de cultura defendido por Said, porém, é o vínculo com a noção de representação, que define a dimensão cultural como uma "estrutura de autoridade e participação" (SAID, 1995, p. 46), uma instância que, estimulada sobretudo pelos aparatos de saber, incorpora e exclui, que legitima e rebaixa. Quando articula as representações ao campo político, Said destaca o caráter construtivo da cultura, um tema que desenvolve desde a publicação de Orientalismo. As representações não refletiriam algo dado ou "real", pronto para ser examinado por análises ou teorias, mas sim um produto criado pelos homens e por condições históricas específicas que engendram um pensamento, imaginário e presença que marcam as relações de poder (SAID, 2007b, p. 31).

0 tratamento da cultura como representação e manifestação do poder é explicitado quando Said relaciona sua reflexão com a diferenciação analítica de Gramsci entre as instâncias da sociedade civil e da política (SAID, 1995, p. 34). Said mostra que a relevância da reflexão gramsciana refere-se ao fato de o poder operar dentro da sociedade civil e suas associações voluntárias, de uma forma indireta e por meio do estabelecimento de uma perspectiva consensual

\footnotetext{
${ }^{3}$ Exemplo importante dessa concepção cultural, Said (1995, p. 80) nota que a idéia goethiana de Weltiteratur - conceito que ficava entre a noção de grandes livros e uma vaga síntese de todas as literaturas do mundo - teve grande relevância para os estudiosos profissionais de literatura comparada no começo do século XX.
} 
que caracteriza os modelos hegemônicos. É nesse sentido que o intelectual tem papel central, tanto na reprodução de uma homogeneidade consensual quanto na consciência da função dos grupos ou classes sociais. Said apropria-se de tal concepção de Gramsci, portanto, no sentido de definir a relação das representações com o pensamento e, por conseguinte, com as formações hegemônicas ou contrahegemônicas. Revela-se, então, um processo que é continuamente recriado e modificado para que a ordem consensual se mantenha e as mobilizações das margens não alcancem relevância. Por sua vez, o resultado dessa concepção, e algo que fica mais claro na análise de Said sobre o imperialismo, é a percepção da política a partir de uma dupla perspectiva, baseada na força e no consentimento, na autoridade e aquiescência. Pode-se relacionar a reflexão de Said sobre o papel das representações na política com a ênfase de Gramsci (1976, p. 49-51) na "relação de forças políticas", momento em que o que está em jogo no domínio ou na sua manutenção, para além das condições econômicas ou de força, são o grau de homogeneidade, a autoconsciência e organização de grupos ou classes sociais para definir uma unidade político-moral que incorpore toda a sociedade.

0 ponto fundamental da análise de Said, nesse sentido, parece ser a suposição de que a cultura é uma arena fundamental do poder e da luta política. A cultura revela as ambivalências da relação entre os processos hegemônicos da representação e as possibilidades de criatividade, situando-se entre o determinismo e a abertura. Além disso, é fundamental notá-la não apenas pelos pressupostos de ilusão ou reflexo das concepções tradicionais de ideologia, mas sim a partir de processos de construção de hegemonias, vinculados a processos de luta política. Entretanto, não se deve situar a teoria de Said como reprodutora de aspectos gerais de autores ou de certa tradição crítica já constituída. Um dos aspectos originais do autor é 0 argumento da importância medular, mesmo na contemporaneidade, das hierarquizações e classificações produzidas pelo discurso imperialista, como se mostrará a seguir. Além disso, é crucial notar como Said ressalta as ambivalências da relação cultura-política, no sentido de tanto revelar o poder das representações quanto o potencial de emancipação. É por isso, por exemplo, que aponta limites na reflexão de Foucault (SAID, 2007a, p. 90; 2002, p. 185). Ainda que seja fundamental notar que o conhecimento se articula com o poder, seria importante também registrar que as capacidades reflexivas não necessariamente tendem a um reducionismo ou a um distanciamento improdutivo. 0 fato é que nenhuma cultura dominante ou representação pode incluir ou esgotar toda a prática. A dialética da cultura aparece mais claramente na discussão sobre 0 imperialismo. 


\section{IMPERIALISMO E RESISTÊNCIAS: AÇÕES POLÍTICAS ENTRE O NACIONALISMO E A MULTICULTURALIDADE}

A concepção de cultura trabalhada por Said, quando articulada com a dimensão política, adquire relevância e originalidade na questão do imperialismo. Said (1995, p. 93) chama atenção para a singularidade de tal relação, já que, mesmo havendo diferentes reflexões sobre as representações, não existiria uma articulação consistente da cultura com a temática imperialista e todas as suas implicações políticas. Um dos argumentos do autor é perceber a perenidade do imperialismo, dado que este não seria, como muitas vezes suposto, apenas a força e o domínio direto ou formalizado sobre um território e realidades sociais distantes (SAID, 1995, p. 40). Ainda que a condição colonial tenha sido praticamente extinta, o imperialismo sobreviveria como poder definido em uma esfera cultural geral baseada, sobretudo, em práticas representativas, além de econômicas e sociais. Tais práticas se expressam em formações ideológicas e, sobretudo, definições binárias que reproduzem a contraposição nós/eles, assim como nacional/estrangeiro, interno/externo, superior/inferior, progresso/atraso.

A importância do conceito na contemporaneidade advém do fato de observar, em algumas situações, o relativo consentimento em uma população distante, principalmente a aceitação da idéia de que certos povos precisam da dominação e controle. Tal fato revela como a concepção de imperialismo leva a reflexão de Said sobre a representação para um parâmetro mais abrangente das relações internacionais. Relacionando experiência, cultura e interesses, as formas de conhecimento destacam-se em tal domínio, tendo papel fundamental os diagnósticos e análises elaborados por instituições científicas, intelectuais e filosofias dos países centrais, que refletem uma "política da interpretação secular" (SAID, 1995, p. 70). Um dos modos de operação da imaginação imperialista é a definição de um alter ego diferente e concorrente. A partir de processos históricos, políticos e intelectuais, elaboram-se, então, identidades parciais que implicam o estabelecimento de opostos, mais particularmente da singularidade de uma sociedade ou comunidade frente a "outros". Ao contrário de serem meras abstrações, tais identidades fundamentam a criação de uma política concreta definida, dentre outras características, pela ortodoxia, por leis excludentes, pela legitimação da violência e por uma política externa de dominação (SAID, 2007b, p. 441-442).

0 vínculo do imperialismo com as representações mostra que o fenômeno não deve ser entendido como resultado direto da dinâmica econômica. Apesar de 
notar a importância de outras análises tradicionais, Said vai além da perspectiva de circunscrever o imperialismo como processo, controlado de modo direto ou indireto, de extração de bens e riquezas materiais de outros países ou de influência econômica para a distribuição de capital excedente. As relações de dependência e controle para Said seriam de outro tipo das que buscam, exclusivamente, uma população a ser utilizada economicamente ou o alcance de novos mercados. $\mathrm{Na}$ verdade, até mesmo tais razões econômicas - que, não obstante, para Said, são fundamentais - seriam consequência de um sistema de pensamento que reflete, sobretudo, uma "vontade" (SAID, 2002, p. 187-188) de compreensão e verdade sobre outras realidades sociais. Isso explicaria por que a condição do imperialismo sobrevive mesmo em países em novas condições de independência, já que reproduzem discursos e instituições das antigas metrópoles, principalmente categorias classificatórias que definem dada homogeneidade contraposta a uma população de "outros" que devem ser silenciados e excluídos.

Segundo Said (1995, p. 177-178), o imperialismo, desde as práticas desenvolvidas pelos europeus no final do século XIX, funciona em formas culturais mais específicas, ainda que sempre baseadas na ideia geral da necessidade de subordinação e vitimização do nativo ou do "outro". Dentro os seus modos, um deles é o prazer no uso do poder, particularmente o poder de observar e controlar.'. Outro consiste no princípio ideológico de reduzir e, posteriormente, reconstruir o nativo como indivíduo a ser governado. 0 terceiro modo seria a difusão da ideia de redenção por meio da missão civilizadora ocidental libertadora. Como ponto fundamental dessas práticas, Said aponta que, em geral, a violência perpetrada pelas práticas imperialistas não é percebida, de modo que não podem ser observadas as mazelas e consequiências de seu poder. Finalmente, deve-se notar o processo pelo qual a história dos nativos é reescrita em função da história hegemônica que utiliza uma narrativa para dispersar outras memórias e ocultar o seu próprio poder, tendo o enfoque de tratar a dominação como necessidade histórica inelutável.

Não obstante, Said reitera em várias passagens de seus textos, sobretudo a partir de Cultura e Imperialismo (SAID, 2002, p. 185-190), a impossibilidade de se pensar o imperialismo sem refletir as resistências a seu processo, o que configura a dialética e ambivalência do processo político fundamentado nas representações.

\footnotetext{
${ }^{4}$ Há aqui um forte eco da relação desenvolvida por Foucault (1988, p. 44-45) entre saber-poderprazer refletida em certos discursos.
} 
0 autor argumenta que tal percepção também é relevante por contrariar um dos grandes silêncios do pensamento hegemônico, que não só interdita, mas rejeita a questão histórica das movimentações emergentes e insurgentes. Um dos objetos centrais de Said para descrever a falta de percepção das resistências apareceria na obra de Joseph Conrad, por exemplo (SAID, 1995, p. 19). 0 problema de seus romances estaria em não entender que os países colonizados também possuíam agentes com identidades não totalmente controladas e potencialmente criativas. Além disso, ao contrário do que Conrad expressava, os movimentos de independência não significavam apenas o advento de governos controlados pelas antigas metrópoles, mas refletiam também capacidades relativamente autônomas que tanto estimulavam a produção de uma nova cultura quanto resgatavam narrativas e histórias anteriormente marginalizadas.

Contudo, nota-se que as resistências não surgem de forma simples, pois obter reconhecimento em novas condições requer ocupar o lugar de representações culturais imperialistas que circunscrevem o "outro" como ser subordinado. Segundo Said (1995, p. 267), a tragédia da resistência surgiria precisamente nas tentativas de recuperação de formas estabelecidas ou influenciadas pela política imperialista - e a luta na África no século XX, que têm como objeto territórios desenhados pelos exploradores, seria o caso mais exemplar dessas dificuldades. Os problemas tornam-se mais efetivos no momento em que as resistências configuram reivindicações locais ou nacionalistas e reproduzem antigas classificações binárias e práticas imperialistas 5 . Dado que a alternativa à condição imperial, principalmente em suas primeiras fases combativas, requer valorizar uma comunidade local e o direito de conceber a sua história e sua memória como um todo coerente, com suas lutas e heróis singulares, surge o perigo dos separatismos e projetos culturalmente excludentes que se baseiam em uma complacência emocional que celebra repetidamente certa identidade.

Assim, embora haja uma visão mais integrativa da comunidade humana e da libertação, sempre há a possibilidade de identidades nativistas romperem com tal padrão (SAID, 1995, p. 274). Nesse ponto, Said (1995) cita a obra de Frantz Fanon para exemplificar as complexidades envolvidas nas resistências, de modo

\footnotetext{
${ }^{5}$ Em uma obra apropriada na reflexão pós-colonialista, Partha Chatterjee (1993, p. 212) mostra como no caso da descolonização indiana o novo planejamento estatal refletiu também uma revolução passiva que não só manteve instituições do período colonial, como preservou a situação de classes pré-capitalistas, tornadas novas aliadas no projeto nacional de modernização voltado, sobretudo, para a preservação da ordem e para o controle de conflitos sociais.
} 
a buscar formas de ação ou concepções nacionais autocríticas não pautadas por narrativas de origens e subjetividades fechadas em que cada um deve "aprender a ficar no seu lugar" (FANON, 1979, p. 39). Fanon seria relevante justamente para a observação da duplicidade da questão nacional, que manifesta tanto um ideal que muitas vezes legitima guerras, xenofobia e regimes autoritários quanto um modelo libertário e criativo de resistência cultural anticolonial (FANON, 1979, p. 128-133). 0 fato é que as potencialidades emancipatórias do nacionalismo se relacionam apenas com o movimento original de descentralização em relação a um poder imperialista, sendo a alternativa nativista, ao contrário, homogeneizadora e necessariamente redutora.

A crítica a certas formas centralizadoras e coercitivas de nacionalismo relaciona-se com o questionamento da formação de imaginários baseados em essências culturais, que na verdade reproduzem as características binárias e excludentes do pensamento imperialista. Said valoriza, por outro lado, o cosmopolitismo e a capacidade criativa da mediação na experiência humana. Normativamente, há três pontos fundamentais que deveriam ser, segundo o autor (SAID, 1995, p. 289), seguidos na identificação e na consciência política. Em primeiro lugar, seria necessário descobrir que o mundo não é construído por essências identitárias em conflito. Além disso, Said defende um universalismo que não seja limitado nem coercitivo em suas formas representativas. Finalmente, o autor argumenta que a identidade local deve ser tida por algo que não esgota a identidade do indivíduo ou de um povo.

Tais pontos normativos se articulam com a crítica da concepção de cultura baseada na valorização irrefletida de certa tradição. Um dos fatos mais problemáticos seria a tendência a ser associada a uma forma excludente de nacionalismo, baseada em uma diferenciação identitária que busca "retornos" a um passado, de modo que a "cultura concebida dessa forma pode se tornar uma cerca de proteção: deixa a política na porta antes de entrar" (SAID, 1995, p. 14). As conseqüências dessa narrativa podem ser devastadoras, dado que, ao lado do "exclusivismo" (SAID, 2007a, p. 74-75) baseado na memória autolisonjeadora de um grupo ou comunidade nacional, nega as realizações dos "outros", concebendo uma hierarquia pronta a legitimar a dominação. 0 importante, portanto, é a crítica da imaginação política de fronteiras rígidas, que se contrapõem a coexistências e à multiculturalidade que necessariamente envolvem as sociedades, principalmente 
na contemporaneidade. Ressaltando o papel das mediações, Said (2000) questiona o "modelo de partilha" predominante nas reivindicações políticas das relações internacionais ${ }^{6}$, que não faria sentido tendo em conta novas condições sociais resultantes dos fluxos de migração, das lutas contra vários tipos de segregação, do surgimento de um conjunto de vozes discordantes, da articulação de minorias e da institucionalização de novos estudos culturais na academia (SAID, 2007a, p. 67-70). Esses fatores reforçam a complexidade e heterogeneidade da realidade social e política, que pede nova abordagem para se examinar adequadamente os processos de identificação social.

Tendo em conta tal multiculturalidade, a questão da identidade nacional e das representações imperialistas se torna problemáticas, sendo papel do intelectual mostrar que as fronteiras não refletem entidade natural ou divina, mas um objeto construído, fabricado e por vezes inventado (SAID, 2005, p. 44). A força dessas representações implica a necessidade de questionar suas imaginações binárias e estáticas em prol da percepção da natureza heterodoxa e complexa da realidade social. Para além de seu caráter normativo, o problema central do orientalismo (SAID, 2007b) seria exatamente a definição de um sistema de pensamento que concebe a realidade complexa, heterogênea e dinâmica do Oriente como uma essência homogênea portadora, em geral, de traços negativos que devem ser controlados e manipulados. Em contraponto ao nacionalismo redutor, a condição de exílio (SAID, 1995, p. 389) seria exemplar em manifestar a capacidade fecunda da multiculturalidade em criar novos tipos de conexões. Ao invés de gerar esquecimento, dominação ou expatriados, o exílio significa uma forma de mediação que estimula a experiência que atravessa fronteiras culturais e desafia limitações nativistas. A condição do exílio constitui, então, uma alternativa ao legado negativo do imperialismo de difundir crenças exclusivistas e inertes, algo contrário ao fato de que os agentes fazem e podem criar suas próprias culturas e identificações.

0 fundamental para Said, portanto, é questionar oposições binárias, mostrando novos alinhamentos desconectados de fronteiras e noções essencialistas. Tal direção aparece contraposta à tendência resultante do imperialismo e do nacionalismo em separar, classificar e hierarquizar culturas distintas? ${ }^{7}$ Por

\footnotetext{
${ }^{6}$ Nota-se aqui coerência do argumento tardio de Said da necessidade de coexistência, em um mesmo Estado, de palestinos e judeus. Said (2000, p. 430-431) defende o potencial de construções de alianças não apenas pautadas por identidades estanques, mas por questões de classe e abrangência política, o que requer, sobretudo, o interesse no conhecimento do "outro".

${ }^{7}$ Tal direção seria exemplar no "confronto de civilizações" de Samuel Huntington, baseada na 
conseguinte, a concepção de identidade requer redefinição, principalmente a imaginação da existência, tida por uma realidade auto-evidente, de um "nós" e um "eles", cada qual muito bem definido e transparente. Em parte devido ao próprio movimento econômico e social do imperialismo, paradoxalmente, as culturas não podem ser pensadas como entidades exclusivas, sendo necessariamente caracterizadas pela interdependência, pelo hibridismo e heterogeneidade.

\section{Considerações Finais}

0 cosmopolitismo presente na obra de Said reflete uma postura política que busca relacionar desigualdades e injustiças de diferentes sociedades, de modo que os modelos de partilha baseados em propostas e representações separatistas se tornam necessariamente problemáticos. Ao invés de mediarem e articularem diferentes grupos ou agentes, tendem apenas a cristalizar diferenças. Said enfatiza, ao contrário, que a tarefa política central, e do intelectual em particular, seria universalizar os conflitos e as crises, dando maior alcance humano aos problemas de povos e grupos. Nesse ponto, deveria haver o resgate de certo legado da filologia, e suas capacidades racionais e seculares, em ter hospitalidade em relação ao outro não familiar, ao invés de se procurar rubricas redutoras e essências exclusivas (SAID, 2007b, p. 19-25). Tal postura relaciona-se à mudança da perspectiva teórica refletida a longo do tempo na obra de Said. Diferentemente do enfoque exclusivo na força redutora das representações que caracterizava seus primeiros trabalhos - deixando pouco espaço, portanto, para as readaptações que os subalternos fariam dos discursos hegemônicos -, o autor busca compreender também em suas análises tardias as mediações e resistências de agente e grupos. A intenção é mostrar, afinal, se, e de que modo, o subalterno pode falar, uma das questões medulares que mobilizam os autores pós-colonialistas. Assim, o desafio enfrentado é avaliar de que modo podem os sujeitos atuar, notando as relações específicas e contextuais com os discursos preponderantes, se há subordinação, readaptação ou contraposição efetiva.

Por outro lado, mesmo tendo em conta o enfoque nas resistências de suas últimas obras, sobretudo a partir de Cultura e Imperialismo, o autor nunca abandona a postura crítica de mostrar os poderosos vínculos do saber com 0 poder e suas conseqüências políticas e imperiais (SAID, 2007b, p. 44-45). 0 ponto

ideia de que as civilizações ocidental, islâmica e confuciana seriam necessariamente essências irreconciliáveis (SAID, 2007b, p. 460). 
fundamental na conjunção desses dois caminhos teóricos é unir a observação de uma agência contra-hegemônica às circunstâncias históricas que definem uma situação de poder. 0 projeto de Said, embora enfatize a complexidade, heterogeneidade e multiculturalidade das sociedades, mostra-se crítico aos pressupostos, particularmente eurocêntricos, que sugerem a impossibilidade de emancipação e esclarecimento. 0 que lhe parece mais consistente nas proposições pós-colonialistas seria justamente a percepção de que, mesmo vigorando grandes representações e narrativas, a realização de projetos de emancipação se faz presente ou permanece latente em vários contextos sociais (SAID, 2007b, p. 463). Portanto, a agência proposta por Said vai de encontro aos argumentos anti-humanistas do pós-modernismo ou de certas tendências pós-estruturalistas críticas a metanarrativas ou ao universalismo da tradição iluminista (SAID, 2007a, p. 28-29) ${ }^{8}$. Said argumenta que essas tendências podem ser claramente questionadas devido ao fato de as pessoas, em geral, serem movidas por ideais de justiça e igualdade provenientes de certa tradição humanista.

Said, nesse ponto próximo das reflexões de Gayatri Spivak (1994), embora ressalte a ambivalência e incompletude das representações e do poder, não aceita teses que enfatizam o local e o contingente e desvalorizam a história e determinações econômicas, criticando suposições de um sujeito com plena capacidade de agir autonomamente (SAID, 2007b, p. 463-464). Sua teoria expõe a relação necessária entre condicionamentos socioeconômicos e as representações, reelaborando a tese gramsciana da política como instância composta de força e consenso, pois a luta pela geografia, e a luta política em geral, "é complexa e interessante porque não se restringe a soldados e canhões, abrangendo também idéias, formas, imagens e representações" (SAID, 1995, p. 37-38). Daí a importância da diferenciação dos conceitos imperialismo e colonialismo, já que a força do primeiro está justamente no fato de ser difuso e corresponder ao controle ideológico de um território distante, ao contrário da dominação direta e formalizada do último (SAID, 1995, p. 40).

\footnotetext{
${ }^{8}$ Dentre os chamados autores pós-colonialistas, a teoria do sujeito de Homi Bhabha, manifestando características da reflexão pós-estruturalista, é a que mais se diferencia da ênfase de Said na força das representações. Bhabha prefere enfatizar a capacidade de agência e a fluidez das interseções híbridas dos indivíduos que ocorrem desconectadas dos aparatos pedagógicos, de modo que sobressaem fatos abertos e incertos da significação cultural. Assim, ressalta-se a possibilidade de uma subjetividade livre de questões de origem e vinculada a princípios vivos do presente, ou ao que pode ser denominado "performance" (BHABHA, 1994, p. 208-209).
} 
Entretanto, mesmo tendo em conta o potencial teórico das propostas de Said, é preciso destacar dois pontos específicos que parecem pouco desenvolvidos em sua reflexão. Em primeiro lugar, ainda que Said note processos e situações sistêmicas que condicionam as possibilidades de ação política, a questão poderia ter sido melhor desenvolvida. Um tema que permanece sem definição clara é a avaliação precisa de quais mecanismos singulares possibilitam 0 afastamento de ações emergentes e criativas dos aparatos discursivos que buscam controlar os agentes. 0 importante é que as lutas incorporam um aspecto relacional que implica ações passadas e reações a grupos opostos, de modo que parece não haver sentido pensar o campo da política sem conflito estruturado e sem a contraposição de projetos e planos demarcados.

Outro possível problema da reflexão de Said é a tendência a não perceber potenciais progressistas em certas imaginações nacionais. A despeito do fato de parte do ideário nacional incorporar, indubitavelmente, uma concepção estática de cultura, parece relevante, por exemplo, o resgate de antigas concepções nacionais de pensadores do século XVIII e XIX, que enfatizavam as potencialidades da soberania popular (BREUILLY, 2000, p. 175; HOBSBAWM, 2000, p. 273). A nação também expõe a relação positiva entre um projeto estatal que busca legitimação e um sujeito popular que é anterior ao Estado (RINESI, 2004). Nesse sentido, ainda que se aponte para a potencialidade política efetiva de uma enunciação cosmopolita e híbrida, parece inconsistente a tese de valorizar, quase exclusivamente, um "estrangeiro universal" ou exilado, desvinculado de qualquer esfera sociopolítica formalizada (BANETH-NOUAILHETAS, 2006, p. 71).

De todo modo, a reflexão de Said, e as implicações de seus conceitos de representação e imperialismo, podem ser fecundas por indicarem caminhos teóricos originais para abordar fenômenos identitários contemporâneos. A questão que parece mais relevante é mostrar como certos entendimentos tradicionais não percebem relações complexas e abrangentes entre as esferas da cultura e da política. A cultura, nesse caso, também deve ser vista como dimensão constituinte da realidade política e não apenas como mero reflexo de uma instância estrutural, algo que transparece por vezes em abordagens das ciências sociais (BHAMBRA, 2007). Ainda que se revele a força de um sistema representativo, é exatamente pela irregularidade e abertura da cultura que se expressa a possibilidade de outro arranjo político, mais particularmente de uma agência simbólica que subverta a predeterminação de certos discursos. 


\section{REFERÊNCIAS}

BANETH-NOUAILHETAS, Émilienne. Le postcolonial: histoires des langues. Hérodote. Revue de Géographie et de Géopolitique, n. 120, 2006.

BHABHA, Homi. The location of culture. Routledge: London, 1994.

BHAMBRA, Gurminder K. Sociology and postcolonialism: another 'missing' revolution? Sociology, n. 41, p. 871-884, 2007.

BREUILLY, John. Abordagens do nacionalismo. In: BALAKRISHNAN, Gopal (Org.). Um mapa da questão nacional. Rio de Janeiro: Contraponto, 2000. p. 155-184.

CHATTERJEE, Partha. The nation and its fragments: colonial and postcolonial histories. Princeton: Princeton University Press, 1993.

EDER, Klaus. Identidades coletivas e mobilização de identidades. Revista Brasileira de Ciências Sociais, v. 18, n. 53, p. 5-18, out. 2003.

FANON, Frantz. Os condenados da terra. Rio de Janeiro: Civilização Brasileira, 1979.

FOUCAULT, Michel. História da sexualidade I: a vontade de saber. Rio de Janeiro: Graal, 1988. . A ordem do discurso. São Paulo: Loyola, 2001. . Em defesa da sociedade. Curso no Collège de France (1975-1976). São Paulo: Martins Fontes, 2005.

GRAMSCI, Antonio. Maquiavel, a política e o estado moderno. Rio de Janeiro: Civilização Brasileira, 1976.

HOBSBAWM, Eric. Etnia e nacionalismo na europa de hoje. In: BALAKRISHNAN, Gopal (Org.). Um mapa da questão nacional. Rio de Janeiro: Contraponto, 2000. p. 271-282.

LOOMBA, Ania. Colonialism/postcolonialism. Routledge: London: New York, 2005.

RINESI, Eduardo. Nación y estado en la teoría y en la política. In: VERNIK, Esteban (Comp.). Qué es una nación: la pregunta de renan revisitada. Buenos Aires: Prometeo Libros, 2004. p. 169-179.

SAID, Edward. Cultura e imperialismo. São Paulo: Companhia das Letras, 1995. 
. An interview with Edward W. Said. In: BAYOUMI, M.; RUBIN, A. (Ed.). The Edward Said Reader. New York: Vintage Books, 2000. . Power, politics, and culture: interviews with Edward W. Said. New York: Vintage Books, 2002. Representações do intelectual: as conferências Reith de 1993. São Paulo: Cia das Letras, 2005. . Humanismo e crítica democrática. São Paulo: Cia das Letras, 2007a. . Orientalismo: o oriente como invenção do ocidente. São Paulo: Cia das Letras, 2007b.

SPIVAK, Gayatri C. Can the Subaltern Speak? In: WILLIAMS, Patrick; CHRISMAN, Laura (Ed.). Colonial discourse and post-colonial theory: a reader. New York: Columbia University Press, 1994. p. 66 - 111.

WEDEEN, Lisa. Conceptualizing culture: possibilities for political science. American Political Science Review, v. 96, n. 4, p. 713-728, Dec. 2002. WILLIAMS, Raymond. Marxismo e literatura. Rio de Janeiro: Zahar, 1979. 